MATEC Web of Conferences 22,04026 (2015)

DOI: $10.1051 /$ matecconf/ 20152204026

(C) Owned by the authors, published by EDP Sciences, 2015

\title{
Effect of Reinforced Concrete Cracking on Chloride Ion Penetration
}

\author{
Chao Yuan, Yang Li*, Xu Chen \& Wenjie Wang \\ College of Civil Engineering and Architecture, Hubei University of Technology, Wuhan, Hubei, China
}

\begin{abstract}
This article is to explore the effect of conditions of reinforced concrete on chloride ion penetration. The influence of the crack width and the thickness of protective layer were studied. In consideration of the randomness of concrete crack width and the fuzziness of its effect on durability, the fuzzy reliability index calculation method was adopted in this paper to calculate the reliability of crack control criterion. Different thicknesses of protective layer of reinforced concrete specimens were designed, and cracks of reinforced concrete specimens were formed by embedding steel sheet. Then specimens were soaked in chloride solution. Finally, the content of chloride ion in concrete was determined by sampling. The results showed that cracks significantly increased diffusion speed of chloride ion within a certain region and the influence degree increased with the increase of crack width. And the influence of concrete cover thickness and concrete strength level on $\beta \mathrm{w}$ was not significant.
\end{abstract}

Keywords: reinforced concrete; cracks; thickness of protective layer; diffusion speed of chloride ion; durability

\section{INTRODUCTION}

Nowadays, reinforced concrete structure is widely used in the civil engineering field. However, the ageing of reinforced concrete structure is increasingly common, and its durability has become the hot spot and focus in the research of the field of civil engineering. The durability of the concrete structures mainly refers to the ability of maintaining its own work performance under the action of natural environment, using environmental and internal factors of materials, and the main reasons for failure of concrete durability are the carbonation, alkali-aggregate reaction, freeze-thaw damage and corrosion of steel reinforcement, and so on ${ }^{[1]}$. According to statistics, corrosion of steel reinforcement has become the first factor leading to the failure of the durability of the reinforced concrete structures ${ }^{[2]}$. The causes of corrosion of steel reinforcement are believed to be carbonation and chloride ion erosion, and chloride ion erosion is the main reason

The transmission mode of the chlorine ion in the concrete mainly includes diffusion, permeability and capillary adsorption ${ }^{[3]}$, and so on. As for the saturated concrete, its capillary suction is zero, so the transmission of the chlorine ion mainly is caused by diffusion ${ }^{[4]}$ Cracking of the concrete structures is often unavoidable because of some factors that include load, change of environmental temperature, dry-wet circulation effect and so on in practical engineering ${ }^{[5-7]}$. While many studies have found that cracks have the influence on transmission of chloride ion in the concrete. Mustafa Sahmaran ${ }^{[8]}$ studied the relationship between the transverse crack width and chloride ion diffusion. The results showed that only if its width was greater than $135 \mu \mathrm{m}$ did cracks have a significant influence on the chloride

*Corresponding author: liyang04201@,126.com ion diffusion coefficient and that diffusion coefficient of the cracking concrete is 1-2 orders of magnitude larger than that of non-cracking concrete. Samaha and Hover

${ }^{[9]}$ studied the effect of cracks on the chloride ion penetration by the method of RCPT. The results showed that the cracks whose width were less than $200 \mu \mathrm{m}$ would have little impact on chloride ion penetration and the cracks whose width were between $200 \mu \mathrm{m}$ and $400 \mu \mathrm{m}$ significantly improved the permeability of chloride ion. Therefore, the relationship between cracks and penetration of the chloride ion further studied is of great significance to the prevention of corrosion of reinforcement and the assessment of durability of reinforced concrete structure. Simultaneously, some researchers also found that the thickness of concrete cover also had effects on the durability of reinforced concrete structure ${ }^{[10]}$.

This article is to explore the effect of conditions of reinforced concrete on chloride ion penetration. Different thicknesses of protective layer of reinforced concrete specimens were designed, and cracks of reinforced concrete specimens were formed by embedding steel sheet. Then specimens were soaked in chloride solution. Finally, the content of chlorine ion in the reinforced concrete specimens at the locations of different distance to the crack and the content of chloride ion in the reinforced concrete specimens at different depth of the cracks are measured. Relevant conclusions are expected to provide some references for the analysis of the durability of the reinforced concrete structure in the chlorine salt environment.

\section{EXPERIMENTAL STUDY}

\subsection{Design of specimens}

According to the purpose of experiment, two different 


\section{MATEC Web of Conferences}

protective layer thickness of $400 \mathrm{~mm} * 100 \mathrm{~mm} * 100 \mathrm{~mm}$ reinforced concrete specimens were designed, and cracks were formed by embedding steel sheets whose width were different, as was shown in Figure 1 and Figure 2. The raw materials of concrete included 42.5 ordinary Portland cement, gravel whose diameter ranged from $5 \mathrm{~mm}$ to $25 \mathrm{~mm}$ and natural river sand whose fineness modulus was 1.62 . HRB400 reinforcement whose length is $600 \mathrm{~mm}$ and diameter is $16 \mathrm{~mm}$ was used. The rigidity of the steel sheet is large. The designed strength grade of concrete was $\mathrm{C} 30$, and mixture ratio was shown in Table 1.

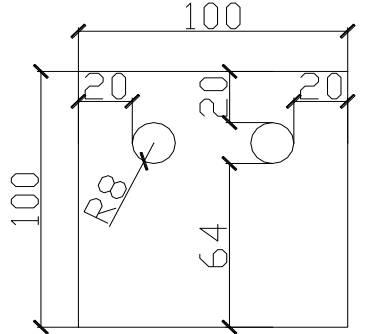

(a) Profile design

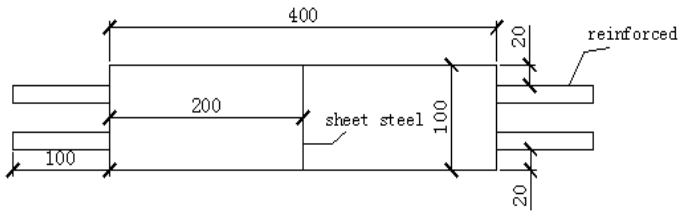

(b) Elevation design

Figure 1. Configuration of test sample 1

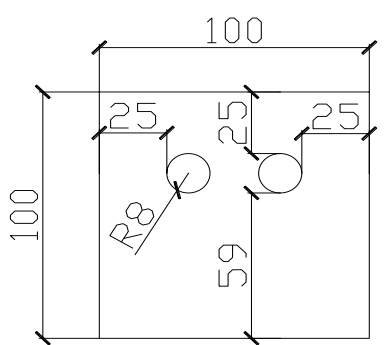

(a) Profile design

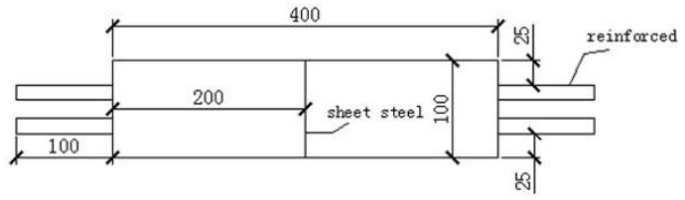

(b) Elevation design

Figure 2. Configuration of test sample 2
Table 1. Mix proportion of one cubic concrete

\begin{tabular}{lllll}
\hline$w / c$ & cement $/ \mathrm{kg}$ & water $/ \mathrm{kg}$ & gravel $/ \mathrm{kg}$ & sand $/ \mathrm{kg}$ \\
\hline 0.42 & 42.5 & 180 & 1245 & 535 \\
\hline
\end{tabular}

\subsection{Steps of experiment}

\subsubsection{Maintenance of specimens whose cracks were} formed by embedding steel sheet

According to the design in practice, reinforced concrete specimens were made. The embedded steel sheets with the thickness of $0 \mathrm{~mm}, 0.25 \mathrm{~mm}$ and $0.5 \mathrm{~mm}$ were adopted. Specimens are numbered after maintained 28 days under the natural environment. Parameter of specimens which have different numbers was shown in Table 2. Figure 3 is the picture of maintenance of specimens.

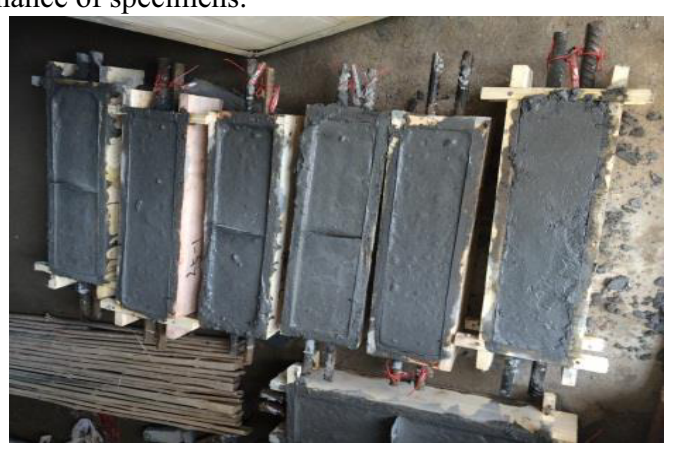

Figure 3. Maintenance of test samples

Table 2. Parameter list of test samples

\begin{tabular}{llll}
\hline $\begin{array}{l}\text { Number of } \\
\text { specimens }\end{array}$ & $\begin{array}{l}\text { Width of } \\
\text { crack } / \mathrm{mm}\end{array}$ & $\begin{array}{l}\text { Cover thick- } \\
\text { ness } / \mathrm{mm}\end{array}$ & $\begin{array}{l}\text { Diameter of } \\
\text { reinforced } / \mathrm{mm}\end{array}$ \\
\hline A1 & 0 & 20 & 16 \\
A2 & 0.25 & 20 & 16 \\
A3 & 0.50 & 20 & 16 \\
B1 & 0 & 25 & 16 \\
B2 & 0.25 & 25 & 16 \\
B3 & 0.50 & 25 & 16 \\
\hline
\end{tabular}

\subsubsection{Specimens soaked in chlorine salt solution}

In order to ensure that the chlorine ion can be diffused to the reinforced only by the prefabricated crack, all the surface of the specimens was sprayed epoxy resin except the cracked surface. Then all the specimens were placed into a plastic box which had been pumped into the $5 \% \mathrm{NaCl}$ solution and the cracked surface was upward. In order to reduce the water evaporation, the box was draped in the plastic film. The content of chloride ion was measured after the specimens had been soaked for 30 days. The experiment was conducted in the standard curing room (temperature $20 \pm 3$ degree, humidity is more than $95 \%$ ). In order to ensure that the concentration of solution and immersion depth of the specimens always stay around the initial state, the concentration of solution and immersion depth of 
the specimens were inspected every three days and the solution was replenished during the experiment. Figure 4 is the picture of specimens in the chloride solution.

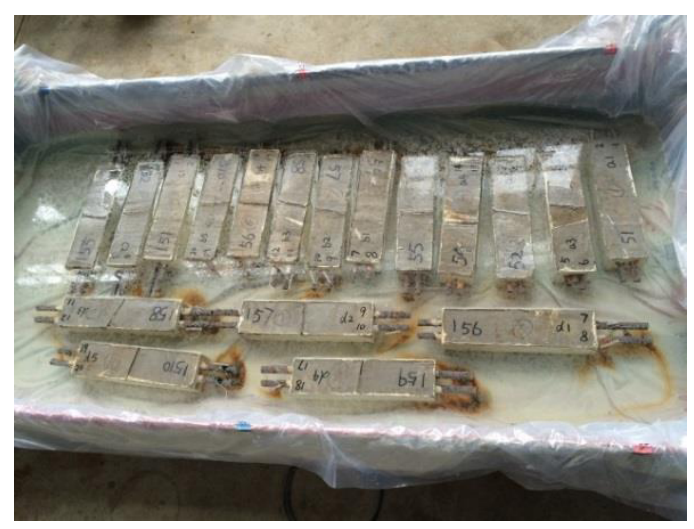

Figure 4. Test samples in the chloride solution

\subsubsection{Sample and determination}

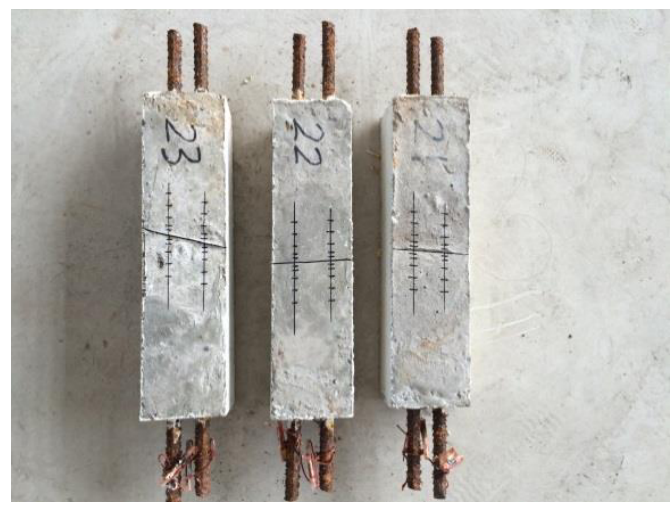

(a) Specimens

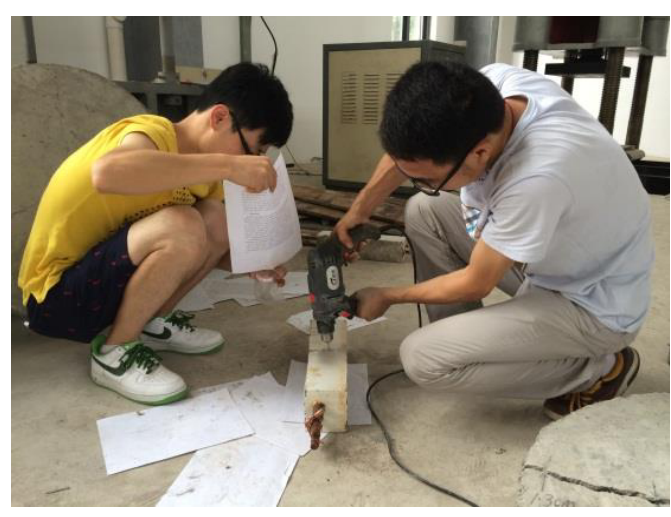

(b) Drilling dust

Figure 5. Sampling of the test samples
Specimens were taken out after being soaked in chlorine salt solution for 30 days. Sample powder was taken by the electrical impacted drill whose diameter of bit is $10 \mathrm{~mm}$ at the upper surface and flank. At the upper surface, sample powder was taken at the locations of different horizontal distances to the cracked section. At the flank, sample powder was taken at different vertical depths along the crack. The horizontal distances and the vertical depths included $5 \mathrm{~mm}$, $10 \mathrm{~mm}, 20 \mathrm{~mm}, 35 \mathrm{~mm}$ and $50 \mathrm{~mm}$. The weight of sample powder was $1.5 \mathrm{~g}$ in each case. Then Sample powder was made into solution. Finally, the content of chlorine ion was determined with ion selective electrode method by NCL-AL chloride ion content detector. Figure 5 is the picture of sampling.

\section{RESULT OF EXPERIMENT AND ANALYSIS}

\subsection{Influence of crack width}

Figure 6 are the graphs that show the relationship between the content of chlorine ion (percentage of total weight of sample powder) and different horizontal distances to the cracked section, including group A and group B. At the horizontal distance of $5 \mathrm{~mm}$, the content of chlorine ion of specimens whose crack width is $0.5 \mathrm{~mm}$ is $1-2$ times larger than that of non-cracking specimens and larger than that of the specimens whose crack width is $0.25 \mathrm{~mm}$ either in group A or in group B. At the rest of the horizontal distance to the cracked section, the content of chlorine ion of specimens whose crack width is $0.5 \mathrm{~mm}$ is similar to that of non-cracking specimens either in group A or in group B. However, the comparison of specimens whose crack width is $0.25 \mathrm{~mm}$ of group A is very different from that of group B. The results show that cracks significantly increased the lateral diffusion velocity of chloride ion in reinforced concrete in the place which is near the cracked section and the influence degree increase with the increase of crack width The effects of cracks on the lateral diffusion velocity of chloride ion are few in the place which is far from the cracked section. The reasons why the comparison of specimens whose crack width is $0.25 \mathrm{~mm}$ of group A is very different from that of group B are analyzed as follows: (1) The data is not accurate because of the mistakes of experimental operation; (2) The crack of specimens whose crack width is $0.25 \mathrm{~mm}$ of group B is self-sealing because the thickness of the specimens of group B is bigger than that of specimens of group A.

Figure 7 showas the graphs that show the relationship between the content of chlorine ion and different vertical depths along the crack. As for each specimen of group A and group B, the content of chlorine ion decreases with the increase of the vertical depth. At the vertical depth of $5 \mathrm{~mm}, 10 \mathrm{~mm}, 20 \mathrm{~mm}$ and $35 \mathrm{~mm}$, the contents of chlorine ion of specimens whose crack width is $0.5 \mathrm{~mm}$ are much more than that of specimens whose crack width is $0.25 \mathrm{~mm}$ and non-cracking specimens The result showed that cracks significantly 


\section{MATEC Web of Conferences}

increased the longitudinal diffusion speed of chloride ion where the cracks exist and the influence degree increases with the increase of crack width. In Figure 7, the comparison of specimens whose crack width is $0.25 \mathrm{~mm}$ of group A is also different from that of group $\mathrm{B}$, and the curve of specimens whose crack width is $0.25 \mathrm{~mm}$ of group B is basically coincident with that of the non-cracking specimens of group B. Therefore, the self-sealing of specimens whose crack width is $0.25 \mathrm{~mm}$ of group B can be basically determined.

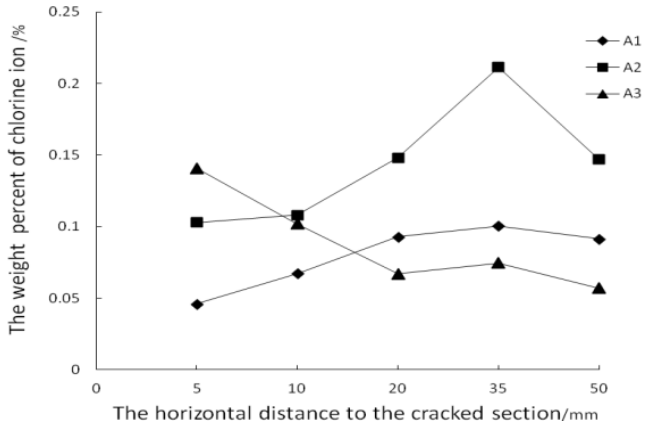

(a) Group A of specimens

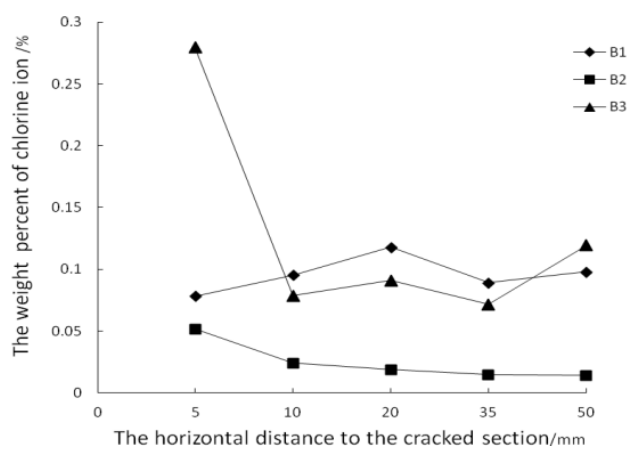

(b) Group B of specimens

Figure 6. The content of chlorine ion in the reinforced concrete specimens at the locations of different horizontal distances to the cracked section

In a word, the cracks of reinforced concrete have a significant effect on the diffusion of chloride ion. Therefore, the control of cracks of reinforced concrete at the chlorine salt environment is important to the prevention of the corrosion of reinforcement. In Figure 6 and Figure 7, the content of chlorine ion of non-cracking specimens is almost less than $0.10 \%$. Some studies ${ }^{[1]}$ have shown that the possibility of corrosion of reinforcement is few when the content of chlorine ion is less than $0.10 \%$ and that the possibility will be greatly improved when the content of chlorine ion is more than $0.10 \%$. That means the non-cracking reinforced concrete has stronger resistance to the immersion of chlorine ion. This is a further indication of the importance of crack control for improving the durability of reinforced concrete.

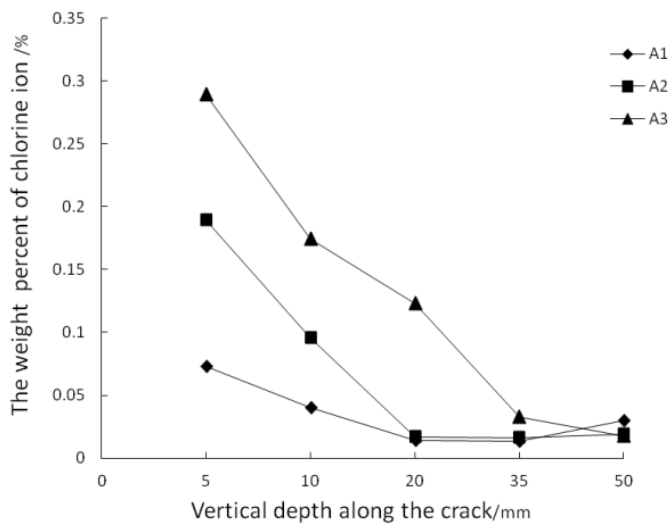

(a)Group A of specimens

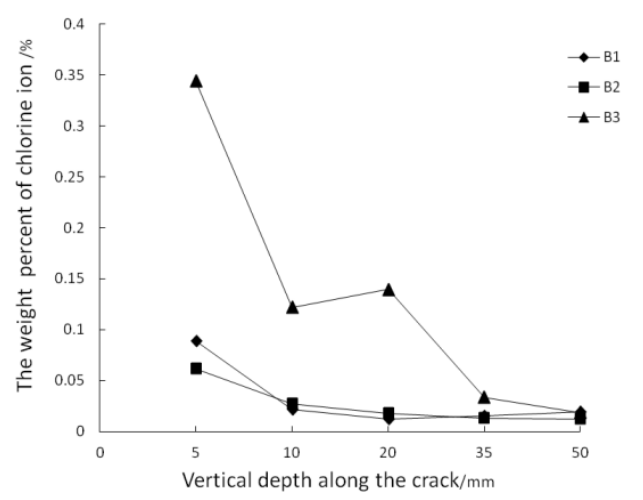

(b) Group B of specimens

Figure 7. The content of chlorine ion in the reinforced concrete specimens at different vertical depth along the crack

\subsection{Influence of cover thickness}

Figure 8 and Figure 9 show the comparison of specimens whose thicknesses are different. Two curves of (b) are very different either in Figure 8 or in Figure 9. Considering the self-sealing of B2 specimens, the results of both graph (b) of Figure 8 and Figure 9 are not considered. In Figure 8, the contents of chlorine ion of specimens whose cover thickness are different are basically the same. So the effects of cover thicknesses on the lateral diffusion speed of the chloride ion are not obvious. In Figure 9, the contents of chlorine ion of specimens whose cover thicknesses are different are also basically the same. So the effects of cover thicknesses on the longitudinal diffusion speed of the chloride ion are also not obvious.

In a word, the influence of the thickness of protective layer on the diffusion speed of chloride ion is not notable. 
ICETA 2015

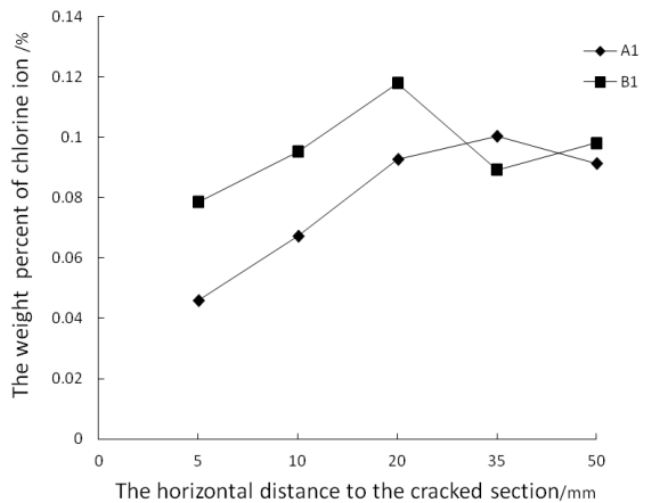

(a)A1 and B1

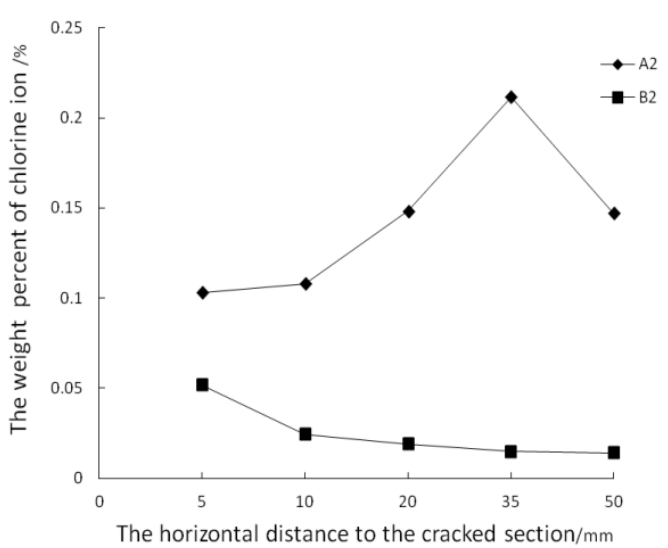

(b)A2 and B2

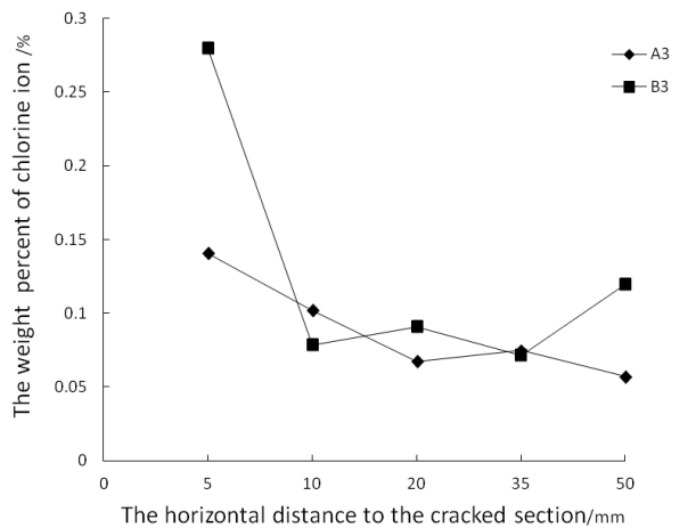

(c)A3 and B3

Figure 8. The content of chlorine ion in the reinforced concrete specimens at the locations of different distances to the crack section
4 CRACK CONTROL CRITERION RELIABILITY INDEX CALCULATION

\subsection{Calculation purpose}

Considering that the main purpose of crack width control is to assure members durability, especially for corrosion environment, however at present the research on relationship between reliability indexes of durability and crack control criterion for durability purpose is not so much. Based on the experiment research above, the relationship between durability reliability indexes and crack control criterion reliability indexes of typical concrete members are researched. Then on purpose of making the crack width control reliability indexes get close to durability indexes for the same environment condition, some revision advice for crack width formula in GB 50010-2010 are provided.

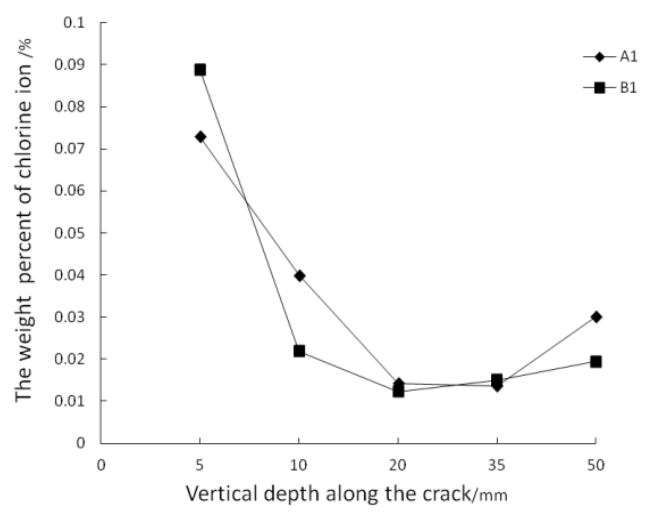

(a)A1 and B1

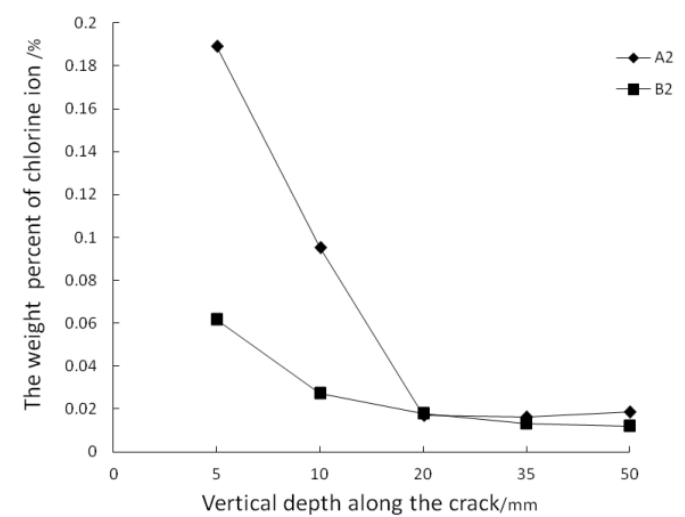

(b)A2 and B2 
MATEC Web of Conferences

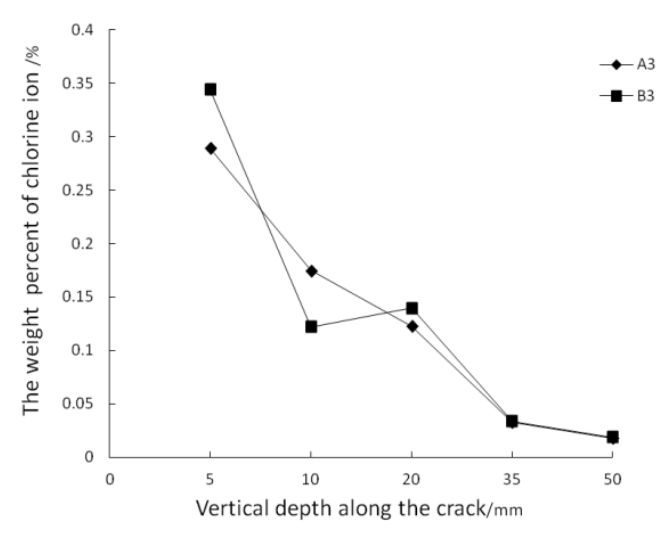

(c)A3 and B3

Figure 9. The content of chlorine ion in the reinforced concrete specimens at different depths along the crack

\subsection{Calculation method.}

For moist or corroded environment, the concrete member transverse crack width control criterion is provided in GB 50010-2010 from the perspective of keeping service function of concrete members. In consideration of the randomness of concrete crack width, and the fuzziness of its effect on durability, the fuzzy reliability index calculation method was adopted in this paper to calculate the reliability of crack control criterion. The durability failure probability induced by concrete crack under service load is as follows:

$$
P_{\mathrm{D} i}=\lambda_{1} \lambda_{2} I\left(w_{\max }^{i}\right)
$$

Where, $\lambda_{1}$ is the synthetic affection coefficient of crack direction; $\lambda_{2}$ is the coefficient of distribution density of cracks, and here $\lambda_{1}=0.4, \lambda_{2}=1.0 ; I(w)$ is the fuzzy indicator function of durability failure induced by cracking.

\subsection{Calculation examples.}

In accordance with reference, typical concrete members are taken as research objects and the environment type is taken as II a. For simplification consideration, three simplified load combinations are chosen respectively. They are dead load and office building floor live load, dead load and residential floor live load, and dead load and shop floor live load. According to GB $50010-2010$, the crack width limit is taken as $0.2 \mathrm{~mm}$. For typical member parameters in Table 1 , the $c-\beta_{\mathrm{w}}$ curves corresponding to different concrete strength level (including C25, C30, C35, and C40) can be gotten where every $\beta_{\mathrm{w}}$ value is the average $\beta_{\mathrm{w}}$ values for 3 kinds of load combination. In addition, the load effect ratio (that is the ratio of dead load to live load) is taken as 1.0. The curves are shown in Figure 10.

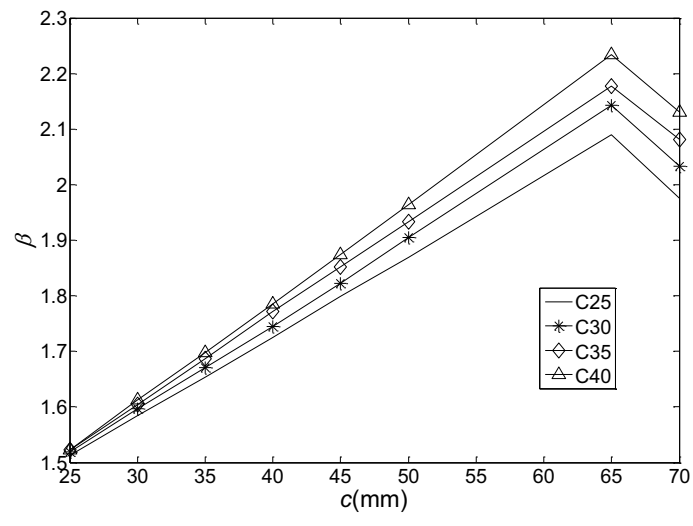

Figure 10. Relationship curves between $c$ and $\beta_{\mathrm{w}}$

From Figure 10, it can be found out that the influence of concrete cover thickness and concrete strength level on $\beta_{\mathrm{w}}$ is not significant. When the concrete cover thickness is increased by $5 \mathrm{~mm}$ the corresponding $\beta_{\mathrm{w}}$ value increment is within $10 \%$, and when the concrete strength is increased by one level the increment percentage of $\beta_{\mathrm{w}}$ is also within $10 \%$. Fuzzy Reliability Calculation for Concrete Crack Control Based on Durability

\subsection{Fuzzy Reliability Calculation for Concrete Crack Control Based on Durability}

(1) Initial corrosion time determination. There have been various carbonation depth stochastic models presented by different researchers at home and abroad. And the models set up by Niu Ditao was chosen in this paper for it not only contains relatively comprehensive factors including the influence of $\mathrm{CO}_{2}$ concentration, environment and construction condition as well as the carbonation position, but it is easy for application. The corresponding calculation formulas are as follows:

$$
X(t)=k \sqrt{t}
$$

$k=2.56 K_{\mathrm{mc}} k_{j} k_{\mathrm{CO}_{2}} k_{\mathrm{p}} k_{\mathrm{s}} \sqrt[4]{T}(1-R H) R H\left(\frac{57.94}{f_{\text {cuk }}}-0.76\right)$

Where, $t$ is the carbonation time/a; $K_{\mathrm{mc}}$ is stochastic variable describing uncertainty in calculation model; $k_{j}$ is corner correction coefficient; $k_{\mathrm{CO} 2}$ is influence coefficient of $\mathrm{CO}_{2}$ concentration; $k_{\mathrm{p}}$ is casting surface modification coefficient; $k_{\mathrm{s}}$ is work stress influence coefficient; $T$ is average temperature per year of environment, degree; $R H$ is average relative humidity per year, $\% ; f_{\text {cuk }}$ is characteristic compressive strength of standard cube of concrete, $\mathrm{N} / \mathrm{mm}^{2}$.

The partial carbonization zone should be considered when forecasting initial corrosion time of steel-bar. The $\mathrm{pH}$ value is normally within the range of 8.5-12.5. When the $\mathrm{pH}$ value reduces to 11.5 , the passive film begins to be destroyed and it is considered to be the sign of initial reinforcement corrosion ${ }^{[3]}$. Supposing the $\mathrm{pH}$ value in carbonation zone is linearly changed 
and considering the influence of carbonation remains, the distance from carbonation zone with $11.5 \mathrm{PH}$ value to complete carbonation zone is as follows:

$x_{1}=0.75 X_{\mathrm{L}}$

Where, $X_{\mathrm{L}}$ is the partial carbonation length, $\mathrm{mm}$.

The equation which describes the partial zone covers the concrete cover completely is as follows:

$X\left(t_{\mathrm{q}}\right)+x_{l}=c$

According to Equation (2) to Equation (5), the initial corrosion time $t_{\mathrm{q}}$ can be gotten.

(2) Calculation examples. This paper makes fuzzy reliability calculation for concrete crack control based on durability by Monte-Carlo method which is recognized to reflect the crack control safety level well at present. Then a comparison of the calculation results between equivalent guarantee rates and fuzzy reliability index will be made to confirm the rationality of equivalent guarantee rates.

This paper adopts the fuzzy reliability calculation method based on durability to compute the crack control reliability index in GB $50010-2010$ by Monte-Carlo method. The whole calculation process is carried out by the software of matlab.

Table 2. Computation results of crack control reliability index for civil buildings

\begin{tabular}{llllllll}
\hline & \multicolumn{9}{c}{ Load effect ratio $\rho$} & Mean \\
\cline { 2 - 6 }$\Psi_{\mathrm{q}}$ & 0 & 0.1 & 0.25 & 0.5 & 1 & 2 & value \\
\cline { 2 - 7 } 0.3 & 1.43 & 1.36 & 1.27 & 1.13 & 0.94 & 0.70 & 1.14 \\
0.4 & 1.43 & 1.38 & 1.32 & 1.23 & 1.10 & 0.94 & 1.23 \\
0.5 & 1.43 & 1.41 & 1.37 & 1.33 & 1.26 & 1.17 & 1.33 \\
0.6 & 1.43 & 1.43 & 1.43 & 1.42 & 1.41 & 1.39 & 1.42 \\
\hline Mean & 1.43 & 1.39 & 1.35 & 1.28 & 1.18 & 1.05 & 1.28 \\
value & & & & & &
\end{tabular}

The calculation condition for reliability index here is the same as the one for equivalent guarantee rate mentioned above. In addition, According to reference [12], this paper chooses typical members as research subject. The height and width of the member section is $400 \mathrm{~mm}$ and $250 \mathrm{~mm}$ respectively. The reinforcement number and diameter is 4 and $20 \mathrm{~mm}$ respectively. The concrete strength level is C30. The crack width limit wlim is taken as $0.3 \mathrm{~mm}$.

When $\Psi_{\mathrm{q}}$ is maintained, the average of the reliability index obtained by different $\rho$ is taken as the final reliability index for the maintained $\Psi_{\mathrm{q}}$.

Table 2 shows the computation results of crack control reliability index for civil buildings in GB 50010-2010.

Table 3 shows the computation results of equivalent guarantee rate for concrete members of civil buildings in GB 50010-2010.

As shown in Table 2, first, the average of reliability index for different $\Psi_{\mathrm{q}}$ is 1.28 more or less, which is lower than 1.74 (showed in bracket in Table 2) as the crack control reliability index provided from GB
50010-2002. In accordance with reference ISO 2394 , for serviceability limit states the target reliability index will be 0 to 1.5 depending on the reversibility of the failure mode. Meanwhile, Reference [1] advises that the target reliability index in relation with durability should be set as about 1.0. All this manifests that the crack control reliability level in GB 50010-2010 meets the expecting demand. Second, with the increase of $\rho$, the reliability index will be lowered markedly. When $\Psi_{\mathrm{q}}$ is 0.3 , and $\rho$ exceeds 1.00 , the corresponding reliability index will be less than 0.9 which shows great unsafety. Third, by comparing the calculation results in Table 1 and Table 2, it is found that the changing regularity of equivalent guarantee rate with $\rho$ and $\Psi_{\mathrm{q}}$ is generally the same as that of reliability index. Because the calculation process of crack control reliability index is too complex, it is necessary and feasible to use equivalent guarantee rate to evaluate the crack control safety level.

Table 3. Computation results of equivalent guarantee rate for concrete members of civil buildings

\begin{tabular}{llllllll}
\hline$\Psi_{\mathrm{q}}$ & \multicolumn{7}{c}{ Load effect ratio $\rho$} \\
& 0 & 0.1 & 0.25 & 0.5 & 1 & 2 & Mean \\
0.3 & 0.95 & 0.92 & 0.86 & 0.75 & 0.58 & 0.39 & 0.74 \\
0.4 & 0.95 & 0.92 & 0.88 & 0.79 & 0.66 & 0.50 & 0.78 \\
0.5 & 0.95 & 0.93 & 0.89 & 0.83 & 0.73 & 0.61 & 0.82 \\
0.6 & 0.95 & 0.93 & 0.91 & 0.86 & 0.79 & 0.71 & 0.86 \\
Mean & 0.95 & 0.93 & 0.89 & 0.81 & 0.69 & 0.55 & 0.80 \\
value & & & & & & & \\
\hline
\end{tabular}

\section{CONCLUSIONS}

This article is to explore the effects of crack width and cover thicknesses of reinforced concrete on chloride ion penetration. Different thicknesses of protective layer of reinforced concrete specimens were designed, and cracks of reinforced concrete specimens were formed by embedding steel sheet. The main conclusions are as follows.

(1) Cracks significantly increased the lateral diffusion velocity of chloride ion in reinforced concrete in the place which is near the cracked section and the influence degree increased with the increase of crack width. The effects of cracks on the lateral diffusion velocity of chloride ion are few in the place which is far from the cracked section.

(2) Cracks significantly increased the longitudinal diffusion speed of chloride ion where the cracks exist and the influence degree increased with the increase of crack width.

(3) The influence of the thicknesses of protective layer on the diffusion speed of chloride ion is not remarkable.

(4) The influence of concrete cover thickness and concrete strength level on $\beta_{\mathrm{w}}$ is not significant. When the concrete cover thickness is increased by $5 \mathrm{~mm}$ the corresponding $\beta_{\mathrm{w}}$ value increment is within $10 \%$, and when the concrete strength is increased by one level the 


\section{MATEC Web of Conferences}

increment percentage of $\beta_{\mathrm{w}}$ is also within $10 \%$.

(5) To realize the goal that the durability design safety level can be generally closest to crack control safety level, two revision advices were presented for present concrete design code GB 50010-2010 to properly lower the crack control safety level in normally moist environment conditions. The present short period crack width enlargement coefficient should be multiplied with 0.85 so that the calculation guarantee rate will be lowered to $85 \%$ for flexural members, and $90 \%$ for axial tension members respectively.

\section{ACKNOWLEDGEMENT}

This paper is supported by "College students' innovative entrepreneurial training program in 2014" (201410500028) and "The Research Fund for the Doctoral Program of Hubei University of Technology" (Q20141403). The author would like to express his gratitude to their support to current research.

\section{REFERENCES}

[1] Jin WL. \& Zhao YX. 2002. State-of-the-art on durability of concrete structures. Journal of Zhejiang University (Engineering Science), 36(4): 371-380.

[2] Jin WL. \& Zhao YX. 2002. Durability of Concrete Structures. Beijing: Science Press.

[3] Mangat PS. \& Molloy BT. 1994. Prediction of long term chloride concentration in concrete. Materials and Structures, 27(6): 338-346.

[4] Wan XM, Zhang FR. \& Zhao TJ. 2001. Mass transfer process in concrete and its theory. Coastal Engineering, 20(2): 73-78

[5] Detroit M. 1972. Control of cracking in concrete structures. Journal of the American Concrete Institute, 69(12): 717-753.

[6] Bentur A. 2001. Early age cracking in cementitious systems. Proceedings of the International RILEM Conference.

[7] Mihashih. \& Wittmann FH. 2000. Control of cracking in early age concrete. Proceedings of the International Work-shop on Control of Cracking in Early Age Concrete.

[8] Sahmaran M. 2007. Effect of flexure induced transverse crack and self-healing on chloride diffusivity of reinforced mortar. Journal of Materials Science, 42(22): 9131-9136.

[9] Samaha HR. \& Hover KC. 1992. Influence of microcracking on the mass transport properties of concrete ACI Materials Journal, 89(4).

[10]LIN YQ. 2013. On concrete protective layer quality and reinforcement corrosion. Journal of Zhejiang Water Conservancy and Hydropower College. 25(2): 17-19.

[11]Wang DZ, Zhang JX. \& Zhang JH. 2006. Investigation on chloride-induced corrosion in reinforled concrete bridge along seaside highway. Journal of Beijing University of Technology, 32(2): 187-192.
[12]Beeby AW. 1979. The Prediction of Crack Widths in Hardened Concrete. The Structural Engineer, 57: 9-17. 